\title{
HEADSET CULTURE, AUDILE TECHNIQUE, AND SOUND SPACE AS PRIVATE SPACE
}

This essay ${ }^{\mathrm{T}}$ offers a story about changing meanings of listening. The techniques of listening that became widespread with the diffusion of the telephone, the phonograph, and the radio early in the twentieth century were themselves transposed and elaborated from techniques of listening developed elsewhere in middle-class culture over the course of the nineteenth century. In other words, they can be located in a genealogy of audile technique, or techniques of listening. By this emphasis on technique I mean to denote a concrete set of limited and related practices of listening and practical orientations toward listening. In The Audible Past, I follow audile technique through three very different cultural contexts: modern medicine in Western Europe and the United States from the I76os into the I90os, American sound telegraphy from the I840s into the I90os, and sound-reproduction technologies in Europe and the United States between I 876 and I930. After introducing the concept of audile technique, this essay picks up the story at the moment audile technique is articulated to the emergent technologies of sound reproduction: sound telegraphy, telephony, phonography, and radio.

As should be obvious from the long time span and diverse contexts that I cover, this is not and cannot be an anthropological history of listening practices. It is not meant as a systematic account of how people actually listened, and it certainly does not pretend to exhaust the descriptive possibilities of listening history or catalog all the contexts in which audile technique plays a role. ${ }^{2}$ My goal is not to describe what it felt like to listen at any given place or time. Nor do I mean to suggest an evolutionary narrative of listening, where the sense of hearing undergoes a naturalized process of modernization. This is why I use the term genealogy: I aim to chart the emergence of a practical orientation in diverse contexts over a long period of time. I am interested in family resemblances among otherwise diverse practices, theoretical or 'idealized' constructs of listening, and how those constructs were supposed to be put into practice. In other words, this is a history of 'regimes' of listening practices. Even if we acknowledge that many of the programs for conduct considered below were never fully realized, they still tell us a great deal about the construction of the institutions and practices that they sought to organize or explain. 


\section{Techniques of listening}

My use of the word technique in relation to listening is derived from Marcel Mauss's notion of 'techniques of the body.' 'The body is man's first and most natural instrument,' writes Mauss:

'Or more accurately, not to speak of instruments, man's first and most natural technical object, and at the same time technical means, is his body.(...) Before instrumental techniques there is the ensemble of techniques of the body. (...) The constant adaptation to a physical, mechanical or chemical aim (e.g., when we drink) is pursued in a series of assembled actions, and assembled for the individual not by himself alone but by all his education, by the whole society to which he belongs, in the place he occupies in it.' ${ }^{4}$

Mauss compiles an extensive list of techniques for investigation: sleep, waking and rest, walking, running, dancing, jumping, climbing, descending, swimming, forceful movements, hygiene, eating, drinking, sexuality, and care of the sick. Although he does not include sensory activities - looking, listening, tasting, smelling, touching - these are certainly implied and even occasionally mentioned in the context of the other techniques. ${ }^{5}$ So my argument makes a very short leap from Mauss's list of techniques to a history of techniques of listening in modernity. It is something of an extrapolation: ethnographers can go somewhere to learn about cultural practices through participation and observation; historians and genealogists must reconstruct domains of physical practice from documents and artifacts. But the issue of technique remains salient.

Techniques of the body are constructed through 'physical education of all ages and both sexes,' and, as we will see, techniques of listening are also the result of physical education, whether this education was institutionalized in professional training or simply accomplished through shared and repeated practice. ${ }^{6}$ The term technique also conjures up names like Aristotle, Martin Heidegger, and Jacques Ellul. It connotes a connection among practice, technology, and instrumental reason: it is a form of 'reasoned production', 'a way of revealing', a 'means with a set of rules for the game.' Under the sign of modernity, technique carries a special value and a special valence - it is connected with rationality. Technique brings mechanics to bear on spontaneity.?

This is an incredibly important point for a history of communication technology: after Mauss, the body is the first communication technology, and all the technologies of listening that I discuss emerge out of techniques of listening. Many authors have conceptualized media and communication technologies as prosthetic senses. If media do, indeed, extend our senses, they do so as crystallized versions and elaborations of people's prior practices - or techniques - of using their senses. So, although technique and technology are terms that clearly bleed into one another, the distinction is crucial for the history of sound. Technique 
connotes practice, virtuosity, and the possibility of failure and accident, as in a musician's technique with a musical instrument. It is a learned skill, a set of repeatable activities within a limited number of framed contexts.

Listening involves will, both conscious and unconscious - perhaps a better word than will would be disposition or even feel. Orientations toward and styles of listening are part of what sociologists and anthropologists have come to call the habitus. Following Pierre Bourdieu, habitus denotes a set of dispositions, what he calls a feel for the game. The habitus is socially conditioned subjectivity: it combines all those forms of informal knowledge that make up social life. Habitus is a mix of custom, bodily technique, social outlook, style, and orientation. Because habitus is socially conditioned, social position and subjective disposition go together-each influences the development of the other. ${ }^{8}$ Industry, bureaucracy, science, rationalism, and the new middle class are all so central to the genealogy of audile technique precisely because techniques of listening represent dispositions articulated within a range of social possibilities.

\section{Orientations to listening}

Modern audile technique combines a relatively stable set of practical orientations toward sound and listening. Although there may be other distinctively modern techniques of listening, the following list represents the orientations common to listening in medicine, telegraphy, and sound-reproduction:

I. Listening gets articulated to notions of science, reason, and rationality. Listening becomes a technical skill, a skill that can be developed and used toward instrumental ends. This is hard to describe, and harder to stress, since there are few English words to connote the sonic equivalents of gazing or observing. We are used to the idea that new orientations toward looking, often thematized as 'the gaze,' have something to do with changing ways of knowing during and after the Enlightenment. As it was for looking, so it was for listening: audition becomes a site through which modern power relations can be elaborated, managed, and acted out. Starting in the select professional contexts of medicine and telegraphy, the very meaning of listening drifts toward technical and rational conceptions. Over the long nineteenth century, listening becomes a site of skill and potential virtuosity.

2. In order for listening to become useful as a tool of rationality (and for itself to be rationalized), it had to be constructed as a discrete activity. In the actual practice of audile technique, listening was separated from other sensory activities. As we will see, audile technique is oriented toward a faculty of hearing that is separated from the other senses. Once so separated, it could be intensified, focused, and reconstructed.

3. Concurrent with the separation of hearing from the other senses is a reconstruction of the shape of acoustic space. Audile technique was not simply a rep- 
resentation of acoustic space; it aimed actively to transform acoustic space. The space occupied by sounds becomes something to be formed, molded, oriented, and made useful for the purposes of listening techniques. It can be segmented, made cellular, cut into little pieces, and reassembled. Acoustic space becomes a kind of bourgeois private space. As I will show, even collective conceptions of technicized listening assumed that collectivity is entered through this prior, private auditory space.

4. As audile technique problematized the shape of acoustic space, it also problematized the content of acoustic space. In audile technique, sounds became meaningful precisely for their sonic and timbral characteristics. On the basis of their sonic character, sounds become signs - they come to mean certain things. Technical notions of listening depend on the establishment of a code for what is heard, but exist without an effective metalanguage. A metalanguage of sound would consist of a nonspecialized set of terms that enabled people to describe the details of audile experience in a purely abstract manner. While visual experience has a well-developed metalanguage, sonic experience does not. We have abstract words to describe color, texture, shape, direction, shading, and so forth. Conversely, most of the language used to describe elements of auditory phenomena is metaphoric: aside from specialized languages in musicology, sound engineering, acoustics, and general descriptors such as loud or quiet, there are very few abstract words in common English for describing the timbre, rhythm, texture, density, amplitude, or spatiality of sounds. ${ }^{9}$ Because of the difficulties involved in constructing a metalanguage of sound, audile technique would come to stress listening practice and practical knowledge through listening, rather than formal and abstract descriptions of sounds.

5. Techniques of listening are based in and described through a language of mediation. Audile technique is premised on some form of physical distance and some mediating practice or technology whereby proximal sounds become indices of events otherwise absent to the other senses. This was in part a component of rationalizing listening and turning it into a skill. It was also in part a component of isolating and intensifying hearing as a faculty.

6 . Finally, audile technique could come to hold a great deal of symbolic currency: virtuosity at audile technique could be a mark of distinction in modern life. Both doctors and sound telegraphers used representations of listening as part of their professional mystique. The more generalized audile technique associated with sound-reproduction technologies was widely understood as an index of those technologies' modernity.

\section{Sight versus hearing}

Speaking generally, audile technique articulated listening and the ear to logic, analytic thought, industry, professionalism, capitalism, individualism, and 
mastery - even as it required a good deal of guesswork in practice. The history of audile technique thus offers a counternarrative to Romantic or naturalistic accounts that posit sight as the sense of intellect and hearing as the sense of affect, vision as the precise, localizing sense and hearing as the enveloping sense. ${ }^{\text {Io }}$ Some medical historians have suggested that there is a uniquely modern medical gaze. If this is the case, then modern orientations toward medical listening were a necessary precondition for this gaze as we know it. If, as many media historians have suggested, electric telegraphy heralds the age of modern mass communication, then listening is at the very core of modern media history. If technologies of sound reproduction depended on and actuated versions of audile technique, they drew together a diverse field of practices that had been developing for decades. To capitalize and commodify sound, sound media industries deployed a preexisting notion of sonic space as private property.

Audile technique emerged as a distinctively modern set of practical orientations toward listening. As a way of knowing and interacting with the world, it amounted to the reconstruction of listening in science, medicine, bureaucracy, and industry. It helped constitute these fields. Audile technique was also a distinctly bourgeois form of listening; it corresponded with the emergence of middle class as a salient cultural category. Thus, the orientations toward listening accompanied sound-reproduction technology in the late nineteenth and early twentieth centuries as part of a longer-term historical current. Many writers in the I920s and I930s pinned radio's cultural significance on its use of hearing as 'a novel sense'. Rudolph Arnheim understood radio perception as a kind of blindness, an aesthetics of the audible with the visual component subtracted. For Hadley Cantril and other radio researchers, radio represented a unique psychological phenomenon, where listening became synecdochic for all activities of audiencing. ${ }^{\text {II }}$ These primarily developmental accounts posit the existence of a history of listening and at the same time close it down - radio, film, and sound recording become the agents of acoustic modernity. They treat sound-reproduction technologies as positing a new way of hearing. In contrast, a genealogy of audile technique shows that over the course of the nineteenth century, audile technique was constructed as a set of related practices. In turn, it was crucial in the construction of sound reproduction as a practice. Thus, my genealogy re-places sound reproduction within the longer flow of sound history.

Audile as an adverb and listening as a verb are deliberate choices on my part. Although my use of audile is somewhat anachronistic (the word first appears in the I88os), its connotations seem especially promising. The word has two primary definitions. As a noun, it refers to a person in whom 'auditory images' are predominant over tactile and visual stimuli. An audile is a person in whom auditory knowing is privileged over knowing through sight. As an adverb or adjective, it means 'of, pertaining to, or received through the auditory nerves' or 'of or pertaining to' the noun sense of audile. ${ }^{\text {I2 }}$ So the term is useful both because it refers to a physiological, process-based sense of hearing (as opposed to older 
terms like auricular) and because it references conditions under which hearing is the privileged sense for knowing or experiencing. This is especially important for the practices that I describe below: hearing is not simply one way of knowing or experiencing among others; it is a sense separated and in some cases privileged (as in doctors' uses of stethoscopes) for particular activities. Thus, I use audile to connote hearing and listening as developed and specialized practices, rather than inherent capacities.

Activity and practicality are also important for my conception of listening. Too often, hearing and listening are collapsed in discussions of the senses. Certainly, hearing is a necessary precondition for listening, but the two are not at all the same thing. The usual distinction is between hearing as passive and listening as active, but this is not quite right either. Hearing is a physical and physiological activity, a form of receptivity. Hearing turns a certain range of vibrations into perceptible sound. Over the course of the nineteenth century, hearing was constructed as a set of capacities and mechanisms, and that mechanical, objectified construct of hearing was crucial in the mechanical construction of sound-reproduction technologies. Audile technique denotes a particular orientation toward listening - but it is not meant to be taken as the only possible orientation toward listening.

\section{Audile techniques and middle-class culture}

Audile technique grew up with the modern bourgeoisie, but it came to music rather late. Audile technique was cultured and developed in relatively circumscribed professional domains of middle-class life. Medicine and telegraphy were two fields where techniques of listening provided professional ethos and prestige. Audile technique functioned as part of the practical and official knowledges of these fields. The use of the stethoscope marked medicine for over a century, and, through its use, hearing surpassed sight as a diagnostic tool. The specificities of listening were themselves able to be applied to the body of the patient; medical listening rendered the interior motions of the human body to medical thought in a new clarity. Sound telegraphy, on the other hand, was the first major electronic medium in the United States, and the development of sound telegraphy represents the instrumentalization of hearing in a bureaucratic-corporate context. Medicine was an upper-middle-class profession, telegraphy a lower-middle-class profession. Both the stethoscope and the telegraphic 'sounder' were technologies that crystallized already-extant techniques of listening. The iconography of listening to early sound-reproduction technologies, especially around ear tubes and headphones, suggests a direct line of descent from the stethoscope and the telegraph to the telephone, phonograph, and radio. Sound-reproduction technologies disseminated and expanded these new technical notions of listening through their own institutionalization. 
From roughly i8io on, audile technique existed in niches at either end of the growing middle class. It would not become a more general feature of middleclass life until the end of the nineteenth-century, when sound reproduction became a mechanical possibility and the middle class itself exploded in size and changed in outlook and orientation. In the meantime, audile technique was a well-known but emergent, specialized practice that helped reconstruct the meaning of listening in modern life.

The two central early sites of audile technique, mediate auscultation (stethoscope listening) and sound telegraphy, shared important characteristics: their articulation to scientific and instrumental reason in clearly defined and framed institutional settings; their practical separation of hearing from the other senses; their reconstruction of acoustic space; their construction of sounds as a primary object of audition; and their powerful symbolic currency in American culture. ${ }^{13}$ These were the same orientations toward listening that would come to be articulated to sound-reproduction technologies, almost from the moment of their emergence. The audile/experiential characteristics attributed to early telephony, phonography, and radio- the problematization of sound and the construction of an auditory field with 'interior' and 'exterior' sounds, the 'extension' and separation of hearing from the other senses, the focus on technique, and the connection between sound, listening, and rationality - were thus refinements and extensions of existing cultural practices.

The growth of the early sound-reproduction technologies would be better characterized as further disseminating previously localized practices than as 'revolutionizing' hearing as such. This section considers that process of dissemination by briefly exploring the diffusion of constructs of audile technique in discourses about listening: especially in images of listening to reproduced sound ranging from I880 through I925. Three aspects of audile technique are especially salient for the images that I consider below: the separation and idealization of technicized hearing; the construction of a private acoustic space; and the subsequent commodification and collectivization of individuated listening.

\section{The individuation of the listener}

Beyond its privileging of sonic details, audile technique is based on the individuation of the listener. The auditory field produced through technicized listening (whether by convention or prosthesis) becomes a kind of personal space. The individual with headphones is perhaps the most obvious example of this phenomenon, and this is why I have chosen to concentrate on images of headphones here. Consider a typical valorization of headphone listening (figure I). A telegraph operator sits in the corner of a train car, shut off from his surroundings by his physical seclusion and the headset that connects him to the railway telegraph. His head is turned down in concentration, and the apparatus sits in 
his lap, yet his posture is one of repose: the slight slouch, the crossed legs. His comfort represents a facility with the machine, a telegraphic literacy. His bodily disposition also represents a separation from the environment: he sits alone in the back corner of the car, his eyes averted from his own environment, his ears covered and linked through the train to the telegraphic network. From the bedside physician in the hospital to the railway telegraph operator in the passenger car, through technology and technique, listeners could transcend the 'immediate' acoustic environment to participate in another 'mediated' linkage.

This isolation and localization of sound and specifically of hearing would be taken to further extremes. Not only was hearing to be separated from the proximal auditory environment, but the act of communication itself was to be separated from the surrounding physical environment. The American Telephone Booth Company hoped to facilitate this framing through physical separation of the telephone from the rest of the office through the use of an indoor phone booth. Here, it is not only the separation of hearing but also the other end of the medium - the isolation of telephonic speech from the rest of the office - that is at stake:

'In order to do away with the noise incident to telephonic service, the Telephone is often put in an out-of-the-way place. These troubles are overcome by using a sound-proof Booth. ${ }^{\text {I4 }}$

The 'trouble' in this case is the intermixture of the sound of telephony with the sound of office work. The booth here serves as a framing device. It reduces the front space of telephonic communication appropriate to that demanded by the conventions of the medium. We can conclude, however, from the fact that telephone booths for offices never caught on, that this particular physical supplementation to the ideological framing of telephony was not necessary to the proper functioning of the medium. On the other hand, the prevalence of telephone booths on streets, in airports, in shopping malls, and in other public places suggests that this construct found other, more fertile niches.

In the phone booth image and the ones that will follow, there is a great deal of attention to (to borrow Reiser's phrase) the isolation in a world of sounds so central to the functioning of sound technology. Audile technique requires the sonic equivalent of private property. This suggests that the diffusion of audile technique is also the dissemination of a specific kind of bourgeois sensibility about hearing and acoustic space over the course of one hundred years. It is no accident that, at each stage of this history, it is an emergent crest of the middle class where one finds these ideas about hearing: doctors seeking middle-class legitimacy in the early and mid-nineteenth century, telegraphers seeking middleclass legitimacy in the mid-nineteenth century, and, finally, the growing consumerist middle class at the turn of the twentieth century and into the i920s, a group of people learning to believe in connections between consumption and 


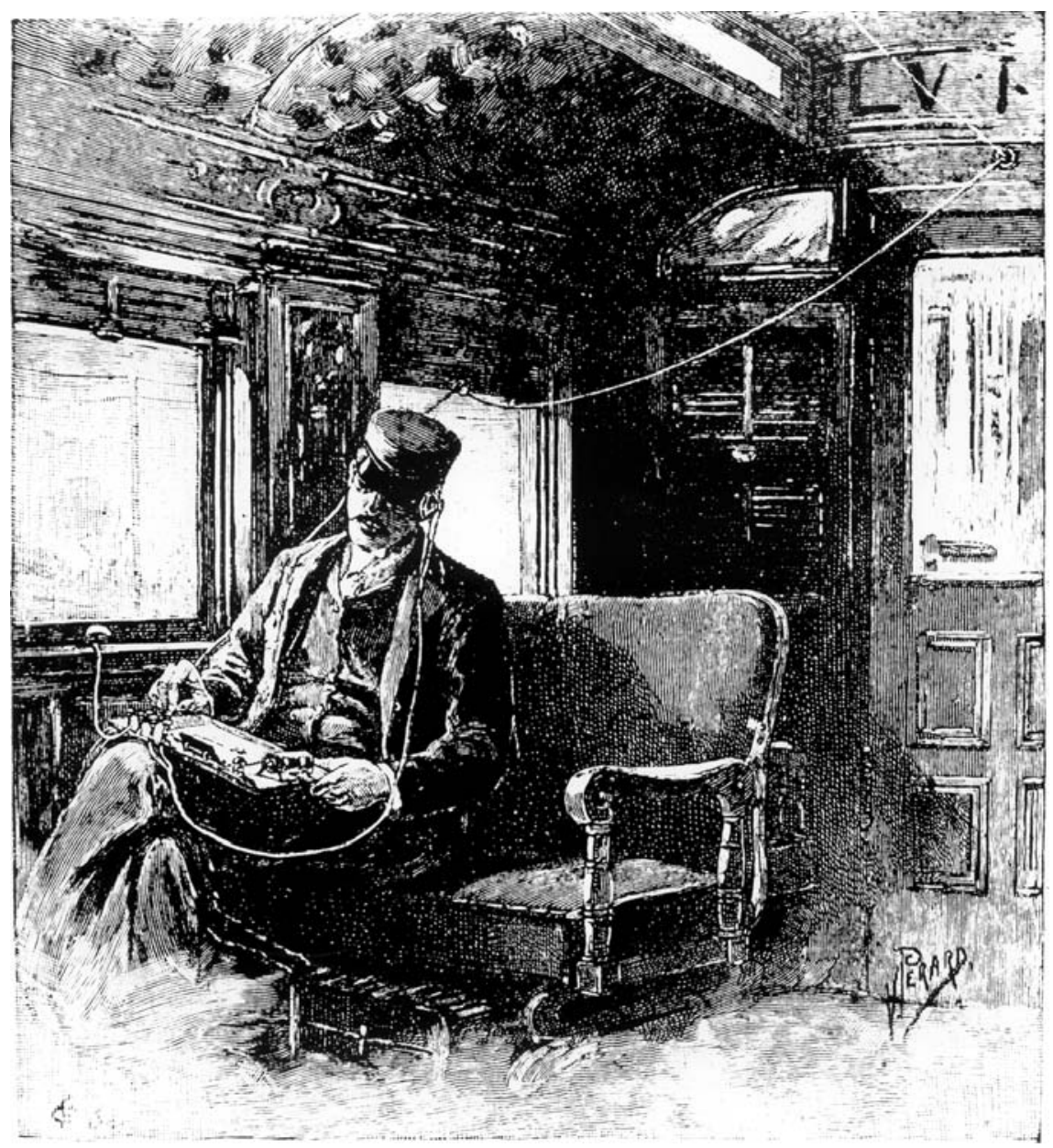

Fig. 1 Train telegraph operator, 1890

individuation. As a bourgeois form of listening, audile technique was rooted in a practice of individuation: listeners could own their own acoustic spaces through owning the material component of a technique of producing that auditory space - the 'medium' that stands in for a whole set of framed practices. ${ }^{15}$ The space of the auditory field became a form of private property, a space for the individual to inhabit alone.

This is not a universal way of portraying listening or even privacy. For instance, In The Sight of Sound, Richard Leppert analyzes a series of seventeenth-century paintings that represent various forms of collective listening. Obviously, paintings of artistocrats and peasants differ in important ways from drawings and engravings of middle-class people in the late nineteenth century. But there are several differences especially relevant for our purposes: the seventeenth-century paintings emphasize place and landscape - they give a sense of where they are located. Sonorial activity was presented outdoors, suggesting the 
expansiveness of sound and, along with distinctions of class and gender, distinctions of species, genus, and kingdom. For instance, Leppert notes that Jan van Kessel the Elder's Bird Concert carefully separated socially significant sound like music from the chirping of birds, submitting the latter to the former, thereby affirming humans' continued dominion over avian species. ${ }^{16}$

As Leppert argues later in the book, it is only in the nineteenth century that an obsession with privacy and domesticity emerges. By this time, the concern is no longer keeping the birds in their proper place on the great chain of being but negotiating social difference among individuals. Painters moved from negotiating differences across species or class to negotiating the spaces between individuals. This coincides with the rise of the bourgeoisie and the codification of art music. Even public spaces become more and more private. Where opera and concert audiences had been noisy and unruly, quieting down only for their favorite passages, they gradually became silent -individually contemplating the music that they had enshrined as autonomous art. We can see a similar trend with the gradual silencing of later audiences for vaudeville and film: as a form of expression becomes more legitimate and more prestigious, its audience quiets down. ${ }^{17}$ This quieting has the effect of atomizing an audience into individual listeners. As we are told today every time we go to the movie theater, in 'observing silence' we respect other people's 'right' to enjoy the film without being bothered by noisy fellow audience members. The premise behind the custom is that, in movie theaters (and a variety of other places), people are entitled to their private acoustic space and that others are not entitled to violate it.

\section{Collective listening}

By the I920s, the possibilities for collective listening to sound-reproduction technologies presumed a prior individuation and segmentation of acoustic space. Acoustic space could be individuated through any number of techniques, all creating an acoustic inside and outside, all shaping the auditory field and emphasizing the detail over the whole. The whole process of technicization operated according to a logic somewhat analogous to a bastardized version of 'social contract' mythology: economic, social, and cultural forces produce property-owning individuals who then perceive themselves as voluntarily entering into a collective and later participating in a 'general will.' The iconography of collective listening embodied this kind of reasoning: the individuated listener comes before the collective sonic experience.

Collective versions of technical listening were designed to allow many people to hear the same thing at once while still putting the sound directly in their ears. In other words, the technicized, individuated auditory field could be experienced collectively. The instructional stethoscope was the first technology developed on this principle. It allowed several students to hear the same sounds at 
once: it attached a single chest piece to many listening tubes. The first such model was designed in I84I, and instructional stethoscopes were in use throughout the nineteenth century. Instructional stethoscopes were doubly useful to medical pedagogy: they modeled, not only the character of the sound to be heard, but also the proper techniques of listening. The instructional stethoscope facilitated listening in a collective yet individuated manner. It is an interesting twist on Reiser's discussion of the physician 'isolat[ing] himself in a world of sounds': ${ }^{18}$ here, the isolation is collective; each student would hear the same things as all the others while still within an enclosed sonic field.

By the early twentieth century, instructional stethoscopes were replaced by electrical stethoscopes that would make the sounds of a

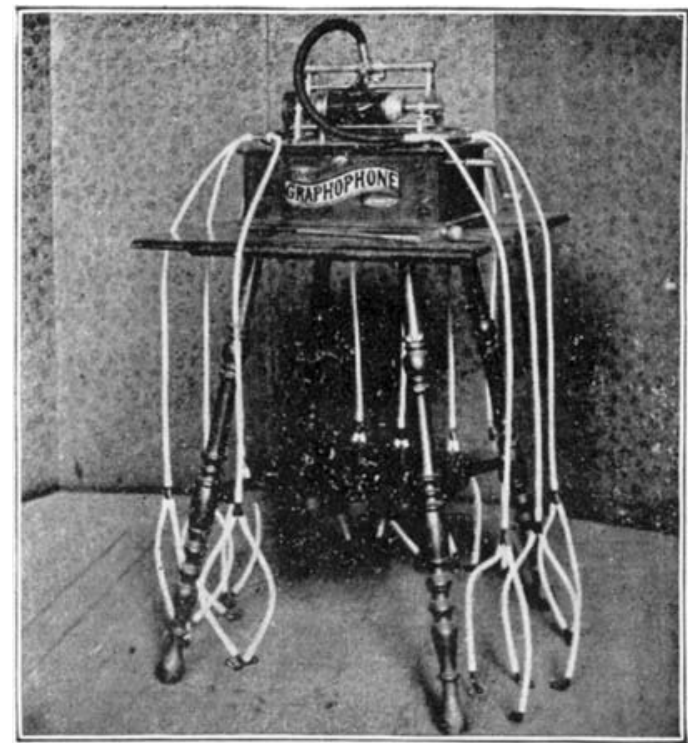

Fig. 2 Hearing tubes in Edison catalog, ca. 1902. Source: National Museum of American History, Washington D.C., USA patient's body audible throughout a room and would amplify sound recordings of heartbeats. ${ }^{\text {I9 }}$ But this notion of collective yet individuated listening persisted elsewhere - both in sound recording and, later, in radio. 'Hearing tubes' were a common alternative to horns on early phonographs (figure 2). They provided a way of increasing the volume of relatively quiet mechanical instruments and also a means of private listening. This mode of listening caught on in private homes, but it was essential for the first context in which the phonograph industry turned a profit: public phonograph parlors that used coin-in-the-slot machines. Phonograph parlors or arcades were a place where commuters (perhaps awaiting a train or a trolley) could stop in for a short time, drop a coin in the slot of a phonograph, and listen to a short tune or sketch. Limiting the sound to one listener at a time helped increase onlookers' curiosity and maximize sales. The phonograph parlor also handily demonstrates the connection between the construction of a private auditory space and the commodification of sound itself.

Put simply, acoustic space modeled on the form of private property allows for the commodification of sound. There needs to be a form of private property before there can be a commodity form - people must be able to own something before it can be bought and sold. Hearing tubes and audile technique construct an individuated, localized sound space, allowing the experience to be sold to a single individual. The patron at the phonograph parlor paid for a certain amount of time in a certain kind of acoustic space. Of course, the practice of sharing ear tubes was quite common in late-nineteenth-century phonograph parlors - each person could put one tube in one ear. But even this sharing was predicated on a 
Fig. 3 Advertisement for the Berliner gramophone. Source: National Museum of American History, Washington D.C., USA

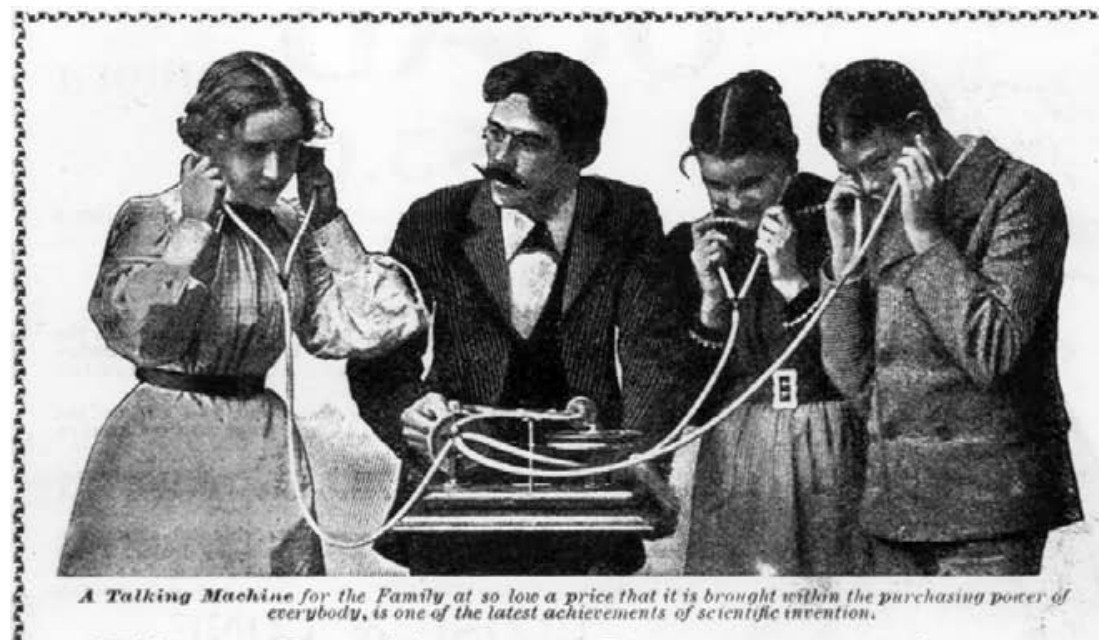

\section{Che Berliner Gram-o-phone}

Talks distinctly, sings every song with expression, plays the piano, cornet. banjo, and in fact every musical instrument with precision and pleasing effect, The plate called ". The Morning on the Farm" gives a perfect reproduction of the lowing of cattle, crowing of the rooster, the call of the hawk, the neigh of the horses, the bleating of the sheep, and in fact every sound which is familiar to the farmyard. The records are endless in variety, including nearly every song your are acquainted with.

Accompanying illustration (above) shows the machine operated with hearing tubes for three people. Tubes for two people go with each machine. Fxtra hearing tubes, so that auy number of people may hear, are furnished at 75 cents extra for each person. Two records are included. with every machine, Extra records 60 cents each, $\$ 6,00$ per dozen.

\section{ALL FOR \$10.00.}

OUTFIT. The Outit includes Talking Machine, Style 7Y, provider with revolving table cuvered

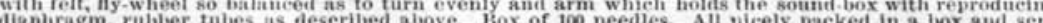
Friced states upon reeeipt of price. Send Money by Postal Note, Express Money-Order or New York Draft.

SPECTAL OFFER, With each Machine ordered before Nov. 10th, ace will include án Amplufying Uorn.

FOR SALE by all MUSIC DEALERS. Send for Catalogue. NATIONAL GRAMOPHONE COMPANY, 874 Broadway, NEW YORK CITY.

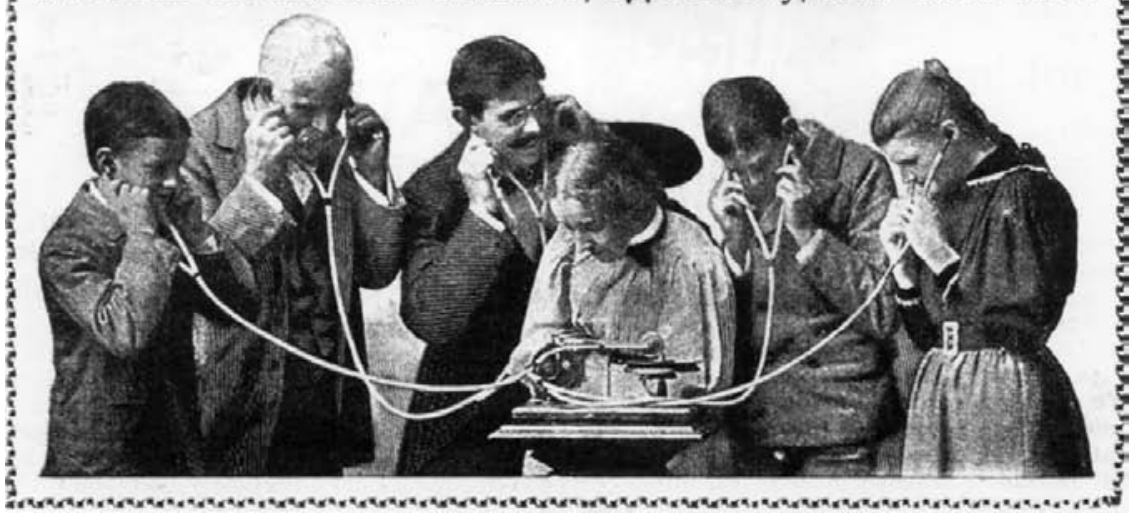

prior individualization. Like any commodity, two or more people could pitch in, purchase it, and share its use. Decades later, an acoustics firm selling its talents to film theater designers would summarize this emergent mind-set: 
'Sound is like other commodities in that there are different qualities - hence different values. Sound for sales purposes (...) costs money to produce. It must be sold at a profit. If the sound merchant does not know how to measure and weigh it, he is out of luck and his profit and loss figures will show up red. ${ }^{20}$

The physical, practical, and metaphoric privatization of acoustic space and auditory experience allowed for sound - the thing in that space - to become a commodity.

\section{Listening to sound reproduction technologies}

Private acoustic space was, thus, a centrally important theme in early representations of sound-reproduction technologies. An advertisement for the Berliner gramophone from the late 1890 s basically updates the imagery and practice of the instructional stethoscope (figure 3). Pictured in a domestic setting, the gramophone is described as an entertainer in the Victorian middle-class household: 'Sings every song with expression, plays the piano...' But the pictures present it as a surrogate for the entertainer: the top photograph depicts a man attending to the reactions of the listeners; the bottom photograph has a woman attending to the machine. In both pictures, the listeners are at attention: their hands at their ears, their faces turned down in concentration (or, in one case, up in delight). These audiences are immersed - 'alone together,' to use William Kenney's phrase - in a world of sound. ${ }^{22}$ The message is one of mediation: listeners isolate themselves in order to have a collective experience through the gramophone.

In his history of recorded music, Kenney writes that listening to sound recording was both an individualized and a collective experience. He conceives of it as "large numbers of individuals around the country and indeed the world, "alone together", actively using their phonographs to replay as they wished commercially mediated musical messages.' Phonographs, 'far from promoting only "ceremonies of the solitary", paradoxically encouraged widely shared patterns of popular behavior, thought, emotion, and sensibility. ${ }^{23}$ Kenney is clearly referring to a geographically and temporally dispersed audience within the United States individual people who listened to the same record in New York, Los Angeles, Duluth, Urbana, and San Antonio and thereby entered into an imagined community of shared musical experience. But his suggestive locution is also applicable to the space around the sound-recording devices in the home. With their ear tubes and postures, the listeners in the Berliner advertisement are also listening 'alone together' to recorded music. Their shared auditory experience is based on a prior segmentation of sound space into auditory private property. 


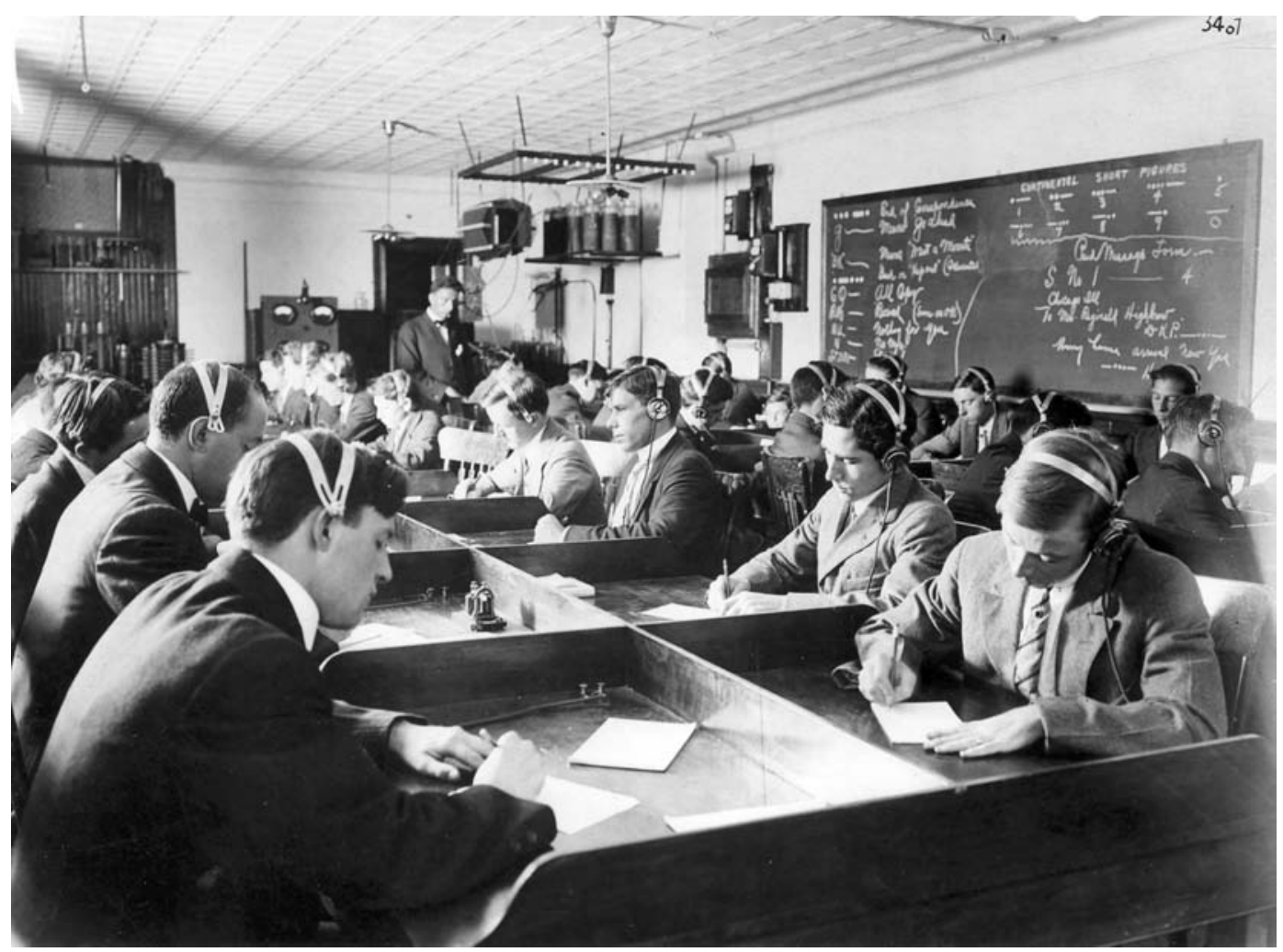

Fig. 4 Students at the Marconi Wireless School. Source: National Museum of American History, Washington D.C., USA

The gramophone may have been a picture of domestic sociability, but the same kind of collectivity could be organized for instructional purposes. Student operators at a Marconi Wireless School (figure 4) are organized in a cellular fashion. Each has his own partition on the desk, and each wears a headset to hear and write down signals. The experience is highly individuated, standardized, yet also collectivized. These Marconi operators are also listening 'alone together.' One assumes that they all hear the same thing, but even that is not necessary for the experience to be collective since they are all inhabiting their private acoustic spaces in their headphones. The framing of the shot focuses on listening to the apparatus: operators turn their faces down, contemplating the signals that they hear and writing them down. The photograph emphasizes the role of training in audition - from the seriousness of the students, to the explanations of code on the board, to the teacher watching over, listening is clearly a skill to be nurtured and developed.

The collectivized isolation of listeners could also become a proper strategy for containing noise and bringing acoustic order to a chaotic milieu. A I923 cartoon (figure 5) dramatically represents the problem of the containment and organization of noise in a domestic setting: a housewife exhausted by the noise 
of the day's household activity finally has peace and quiet when the rest of the family put on their headsets and plug into the radio. This cartoon offers a vision of radio as a pacifier similar to the account of radio offered by social critics of the time: the characters in the cartoon make all sorts of noise until they are quieted - alone together - by the radio set in the living room. The crowd becomes the mass right before our eyes in the Sunday paper.

This image is also interesting because it depicts a form of family togetherness and communal listening that begins from cellular acoustic space. As with the gramophone advertisement, people listen together by using headphones together. But there is a question as to whether the headphones are even necessary in the image here. Within a few years, images of family togetherness around the radio would use loudspeakers instead of headphones. But audile technique would remain. Even in this and other collectivized settings, technique could be the governing mode of listening. As James Johnson said of concert audiences, it was technique that was most likely to 'bridge the inner experiences of a fragmented public. ${ }^{24}$ Even Johnson's locution evokes the prior division of acoustic

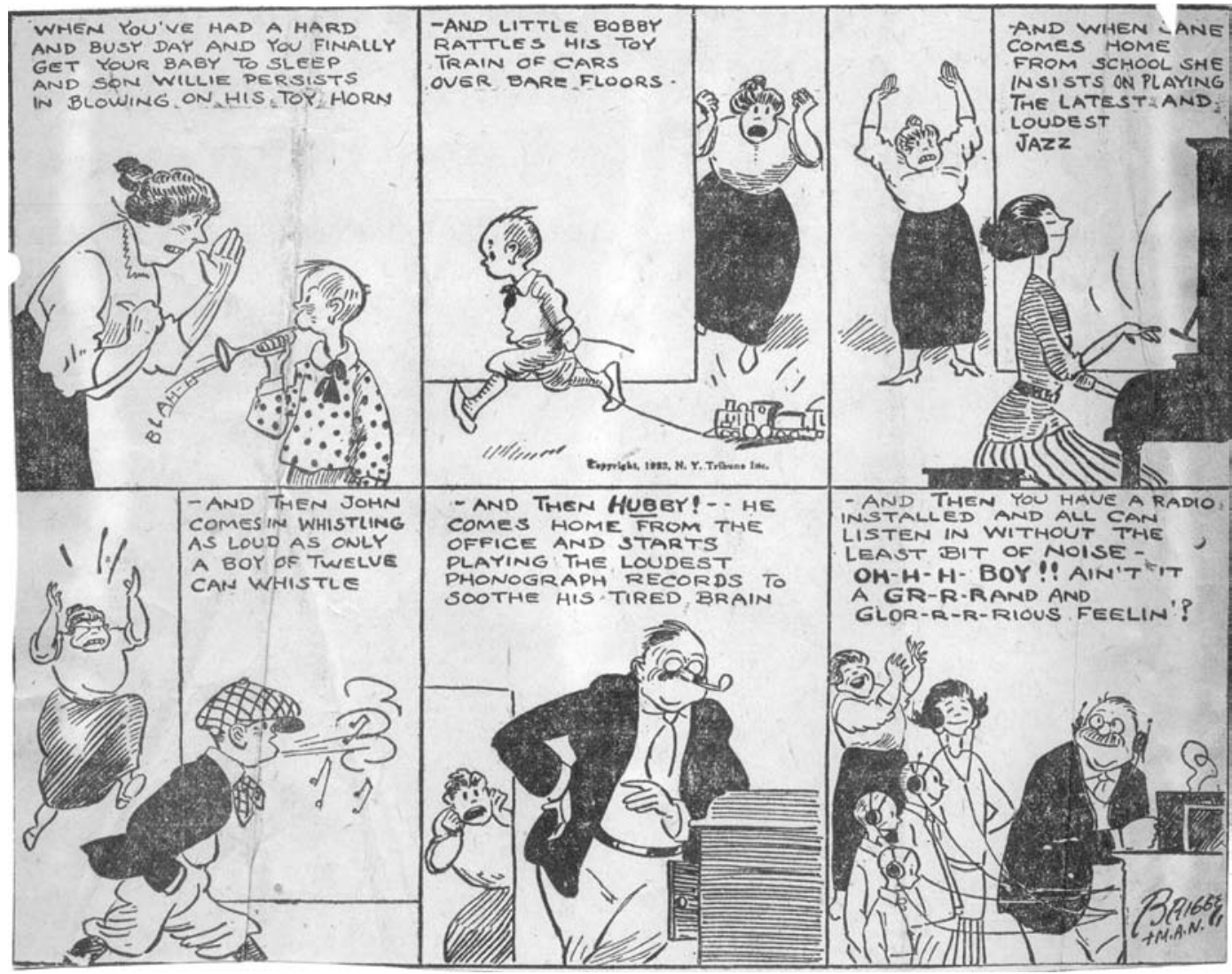

Fig. 5 Cartoon of frustrated housewife, 1923. Source: National Museum of American History, Washington D.C., USA 
5 A

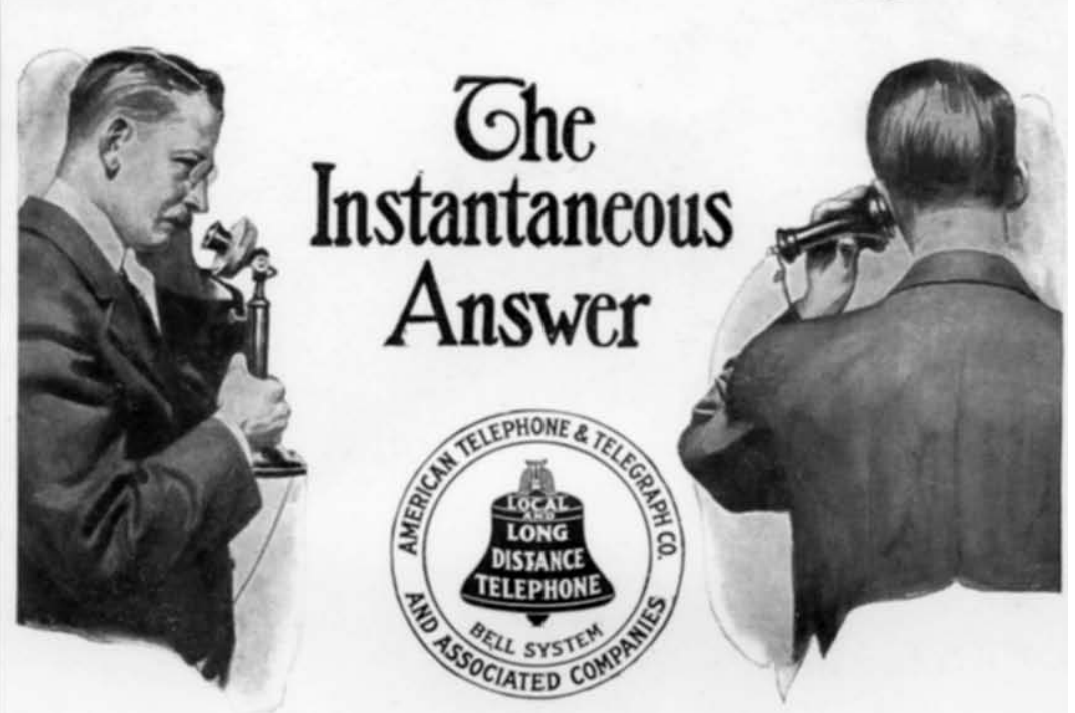

Sending a message is only half of the transaction. The other, and equally important, half consists in getting back the answer.

Sometimes this is a reply to a question, or the acceptance or rejection of a proposal. Sometimes it is simply an acknowledgment that the message has been received.

The value of the message depends upon getting an answer.

When a general manager sends word to a representative in a distant city, he wants to know that his man is there, that he receives the message, and that he will act.

If the answer is not final, but raises another question, there is no delay. The other question can be settled at once. It is possible, in one telephone interview, to come to a decision which could not have been reached without the instantaneous answer.

Each answer is made instantaneous by the Bell telephone service.

The Bell system, with its ten million miles of wire, provides the instantaneous answer for anybody, anywhere, at any time.
Fig. 6 'The

Instantaneous

Answer' - an N. W. Ayer advertisement for AT\&T's phone service, 1910. Source: National Museum of American History, Washington D.C., USA
Increased use of the Long Distance Telephone means greater results in every line of human endeavor. Telephone efficiency means One Policy, One System, Universal Service. Every Bell Telephone is the Center of the System. 
space into private property, since these inner experiences were fundamentally private and, therefore, in need of bridging. A history of group listening to phonographs or radios is obviously a step beyond the history offered in this chapter, but I would predict that, even in these moments of collectivity and togetherness, people's practical techniques of listening involved a certain prior individuation of acoustic space. They entered this audile collective like the mythical individuals who would enter into a social contract: first free and separate and then together. Private acoustic property and the commodity form of sound emerged together.

In the images considered thus far, listening is emphasized through its iconographic relation to looking. Sensory separation and framing of the medium are represented visually through representation of physical posture and downward or otherwise averted or undirected gaze. In each case, the gaze (as it is pictured) is averted, elided, in an effort to represent hearing. Yet even this hearing is a subject of gazing - the viewer implied, not only by the positioning of people's bodies, but also within the frame of the stethoscope, the gramophone, the Marconi school, and the cartoon. Each picture presents a spectator within the frame that could easily be read as an analogue of the spectator outside the frame: in the pedagogical situations, a competent, socially superior observer ensures the solemnity of the situation and guides the ears of those in training. In the domestic scenes, it is a question of attending (in both senses of the word) to others' pleasures through maintaining the operation of the machine and at the same time observing and enjoying others' enjoyment. The collective activities in these events are possible only after the listeners have been individuated - their separation effected through bodily disposition, the mix of prohibition and exhortation enacted through social convention and the ideology of the universal bourgeois individual.

\section{Listening as interconnectivity}

The collectivity represented in this mode is more of an interconnection than anything else - listeners are linked with the network and, through the network, can reach one another. This was Kenney's original point: standardized, commodified music allowed people separated by expanses of time and space to hear the same thing. The same principle works for telephony. The N. W. Ayer Agency, which had a major advertising contract with AT\&T through the I9IOs and I920s, cast telephony in terms of intensification of the expressive and perceptive capacities in hearing. Two advertisements from the agency's vast output can illustrate this tendency (figures 6-7). Telephony not only increased personal agency as a kind of fixed capital - 'the multiplication of power' - but also provided a kind of audile immediacy at a distance previously reserved for the telegraph. The sounds heard on the telephone corresponded to sounds possibly thousands of miles away; proximal sound was linked to distant activity: 'Each 


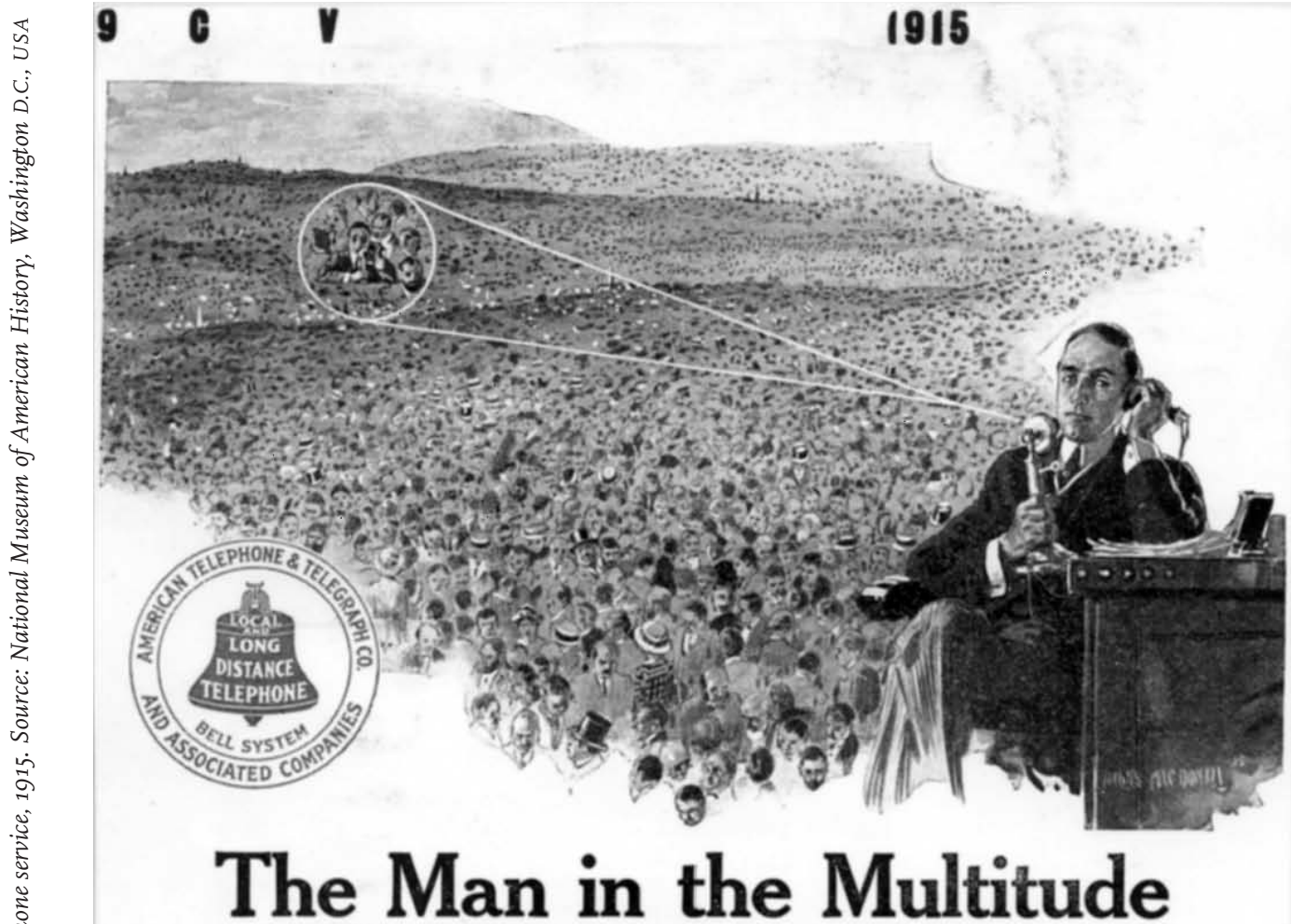

That the human voice may be transmitted across our continent by telephone is the marvel of this age of wonders. Yet the full significance of the achievement is not realized if it is considered strictly as a coast-to-coast connection.

The Transcontinental Line not only bridges the country from east to west, but, by having finally overcome the great barrier of distance, it has removed the last limitation of telephone communication between all the people of the nation.

This means that the voice can be sent not only from New York to San Francisco, but from anywhere to anywhere-even from any one to any one - in the United States.
Wherever you are, it is possible to reach any one of our hundred million population. You can single out from this vast throng any particular individual with whom you desire to speak.

To bring this about, the Bell System has spent years and millions, extending its lines everywhere, anticipating the ultimate triumph. It has had the foresight and the courage to unite this great country, community by community, into one telephone neighborhood.

With success achieved by the Transcontinental Line, the established Bell highways make you, wherever you are, the near neighbor of your farthest-away fellow citizen.

\section{AMERICAN TELEPHONE AND TELEgRAPH COMPANY AND ASSOCIATED COMPANIES \\ One Policy \\ One System \\ Universal Service}


answer is made instantaneous by the Bell telephone service' (figure 6). Even in advertisements for the telephone, however, the medium quickly disappears:

'A generation ago, the horizon of speech was very limited. When your grandfather was a young man, his voice could be heard on a still day for perhaps a mile. Even though he used a speaking trumpet, he could not be heard nearly so far as he could be seen.

Today all this has been changed. The telephone has vastly extended the horizon of speech. Talking two thousand miles is an everyday occurrence, while in order to see this distance, you would need to mount your telescope on a platform approximately 560 miles high'. ${ }^{25}$

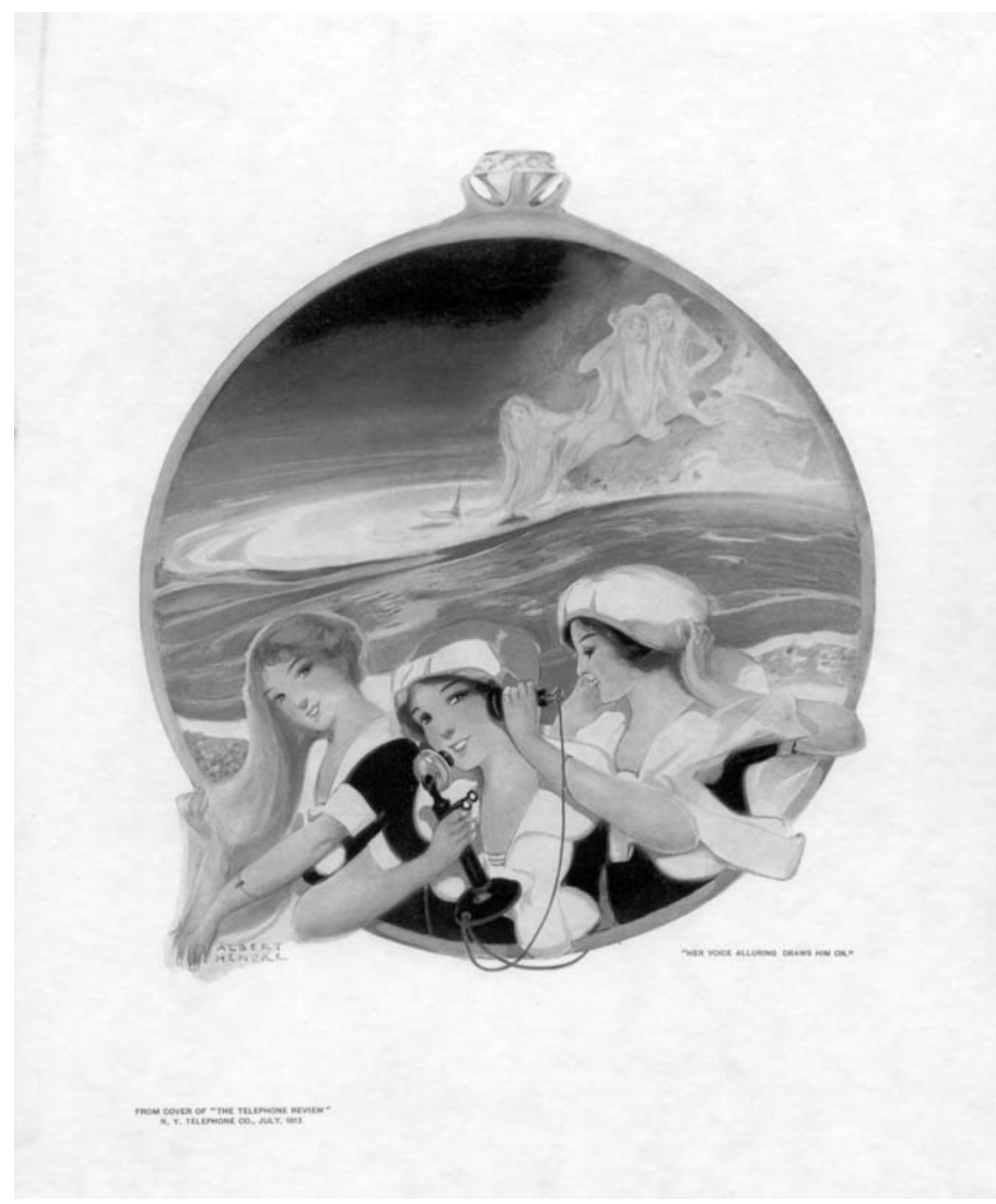

Fig.8 'Her Voice Alluring Draws Him On'- cover of the July 1913 Telephone Review (New York Telephone Company). Source: National Museum of American History, Washington D.C., USA 
This ad copy renders the telephone as a necessary supplement for the deficiencies of hearing or, rather, its 'limited' horizons. As with telegraphy, for a moment ads for the telephone could claim it as the marvel of the modern age, and the ability to hear in new ways was a hallmark of progress and modernity. A variation on this theme can be found in Ayer's 'The Man in the Multitude' (figure 7). Here, a man with a telephone sits in a chair above and to the side of a panoramic view of a great mass of people. He looks down and away from the crowd, like the earlier telegraph operator, his legs are crossed - he is comfortable, at ease, and in command. His hand is to his ear, and his eyes are free to do as they please. In the distance, the picture shows another man with a telephone; a telescopic line connects the two: 'You can single out from this vast throng any particular individual with whom you desire to speak.' Ayer is selling the directionality of audile technique and sound technology as a form of agency - listeners can better direct, orient, and focus the auditory field through its supplementation. Of course, this kind of agency, supplementation, and immediacy was phrased in terms of personal business success. But the logic behind it goes beyond advertising aimed at businessmen. Ultimately, sound-reproduction technologies were portrayed as providing intimacy (erotic, familial, personal) as well as immediacy.

'Her Voice Alluring Draws Him On' is the caption for the cover of the Telephone Review, published by the New York Telephone Company (figure 8). Spilling out of the frame are three young women, the one in the center with a telephone in her hands, her eyes looking directly at the observer - all three are cast in vaguely suggestive poses. In the background is a stormy sea, and in the upper-right-hand corner of the picture reside three sirens perched on an island. This image of telephonic erotics is no doubt still cast with male eyes in mind, but its implication is quite different - here the possibility of telephonic audition is itself rendered as a kind of excess, both sexual and sensual in nature - an intensification, supplementation, and possible supersession of the immediacy of unaided hearing. Again, this image points to a reconstruction of acoustic space: in the space of telephony, the operator's eroticized voice draws in male ears as it comes down the line. Meanwhile, the sirens in the distance look on, silently. Once able to induce shipwreck through merely grazing the ears of male sailors with their voices, they have been overcome by the controlled erotics of modern sound technology. The unruly eros of antiquity, where the male subject could lose control at any moment, has been replaced by a regime of segmentation, distance, self-control, and modulated desire.

The New York Telephone Company anticipates Norbert Elias's riff on Freud and Weber: repression and mediation give us modern life. 'Restraint of the emotions' wrote Elias, became especially important as 'outward differences of rank had been partly levelled.' As gradations of social difference became ever finer and more contingent, physical distance and decorum, which had previously been issues only among social equals, became a more general concern. Technol- 


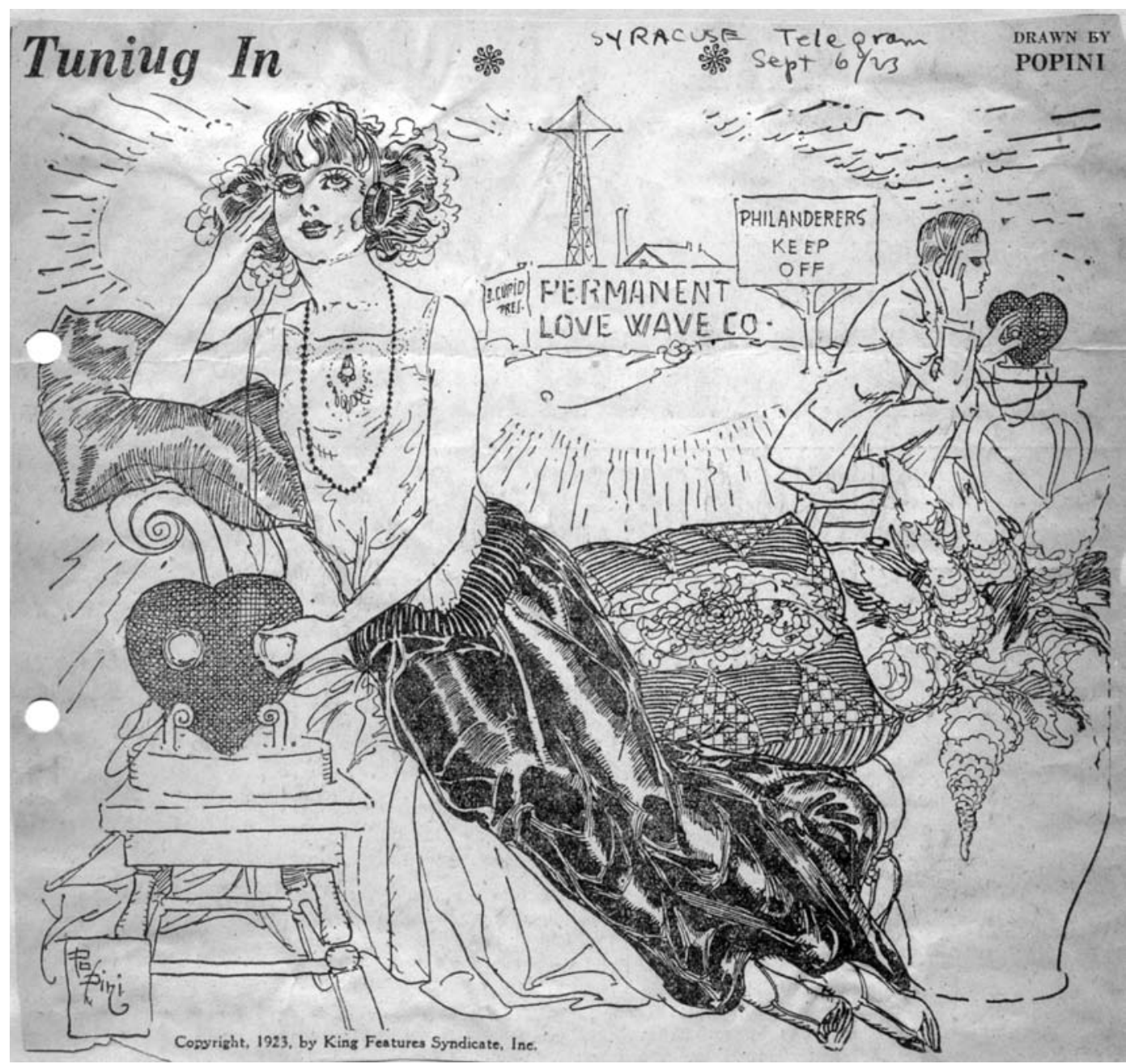

Fig. 9 'Tuning In' - cartoon from the 6 September 1923 Syracuse Telegram. Source: National Museum of American History, Washington D.C., USA

ogies of sound reproduction did not cause this transformation, but they did crystallize it:

'once, in conjunction with a general transformation of human relations, a reshaping of human needs was set in motion, the development of a technical apparatus corresponding to the changed standard consolidated the changed habits to an extraordinary degree. This apparatus served both the constant reproduction of the standard and its dissemination. ${ }^{26}$

The New York Telephone Company's illustration thus indexes an entire middleclass habitus of listening. 
This notion of direct interconnection extended to other, less eroticized, although equally fantastic, scenarios. A I923 cartoon from the Syracuse Telegram (figure 9) pictures a female-male couple wearing headphones plugged into two heart-shaped radios, communicating with one another through the ether. In the distance, a broadcasting station called the 'Permanent Love Wave Co.' is bordered by a sign warning, 'Philanderers Keep Off.' The cartoon thus acknowledges the anxiety around radio communication even as it paints a romantic image of modern love: both the woman and the man hold their hands to their ears, their eyes averted from any kind of direct gaze, their bodies poised in anticipation but still at ease with the medium. The message was clear: the ether was a fertile medium in which to culture the intensity of romantic love, and this intensity could be felt by listening alone together. Even the most intimate social-sonic relations could presuppose the segmentation of acoustic space into private space prior to its collectivization. The warning sign is particularly interesting: it is clearly of a piece with the stories about telegraphic 'crimes of confidence', but, in the context of the picture, it also carries another meaning. It suggests that the ethereal love enabled by radio is a spiritual connection: those who would confuse this deeper intimacy with physical attraction between human bodies should stay away. Once again, the distance between bodies is essential to the conception of private acoustic space and audile technique.

\section{Sound technologies become sound media}

By the early I920s, a visual vocabulary of auditory immediacy had been established. Headphones could appear in almost any situation, as much a symbol of connection to a common commodity culture and of that culture's integration into both domestic and public life as of anything specific about listening. Families, children, adults, and pets all appeared wearing the ubiquitous headphones. Cartoonists, meanwhile, lampooned these conventions, either by mocking onlookers' impressions of technicized listening (figure io) or by making a joke of the 'isolation in a world of sounds' that other media representations cast as both necessary and desirable. These images might be attributed to headphones' status as an easily recognizable trapping of radio technology in general, a status that made them useful to the press depicting a 'radio boom.' But the meaning of the headset was not simply as an index of radio. It was an extension, modification, and refinement of one hundred years' worth of techniques of listening. The private experience of radio listening was certainly different from the private experience of the physician listening to a patient's body, but the two practices bear a striking morphological similarity to one another. Audile technique organized, framed, and conditioned both those experiences.

Over the span of a century, technicized listening moved from an esoteric medical technique that required extended training and explanation to a com- 
Cartoonists' Pens Are Busy with Wireless Witticisms for All SIMEON BATTS
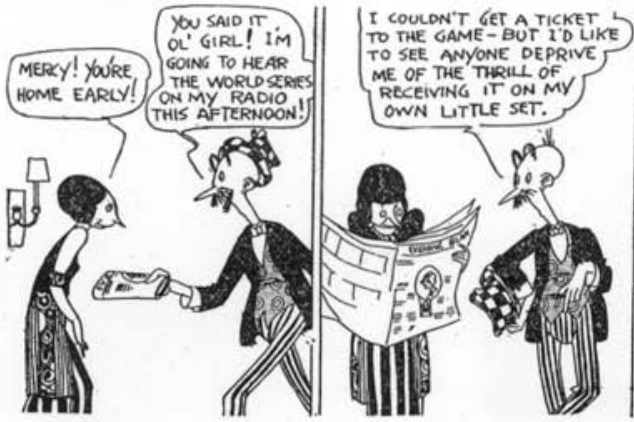

By HAENIGSEN

NEIGHBORHOOD NEWS

By FONTAINE FOX
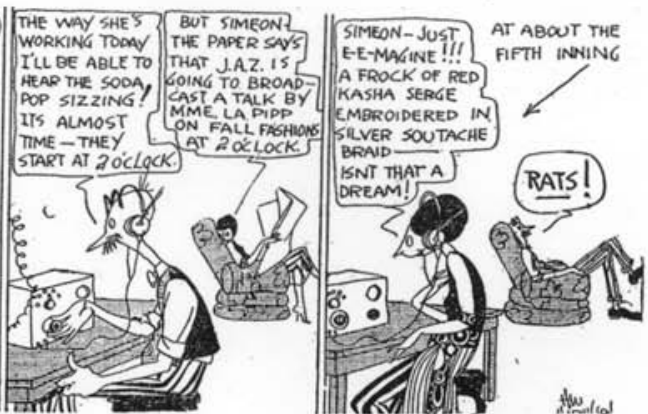

SCHOOL DAYS

$-N, Y, M a$
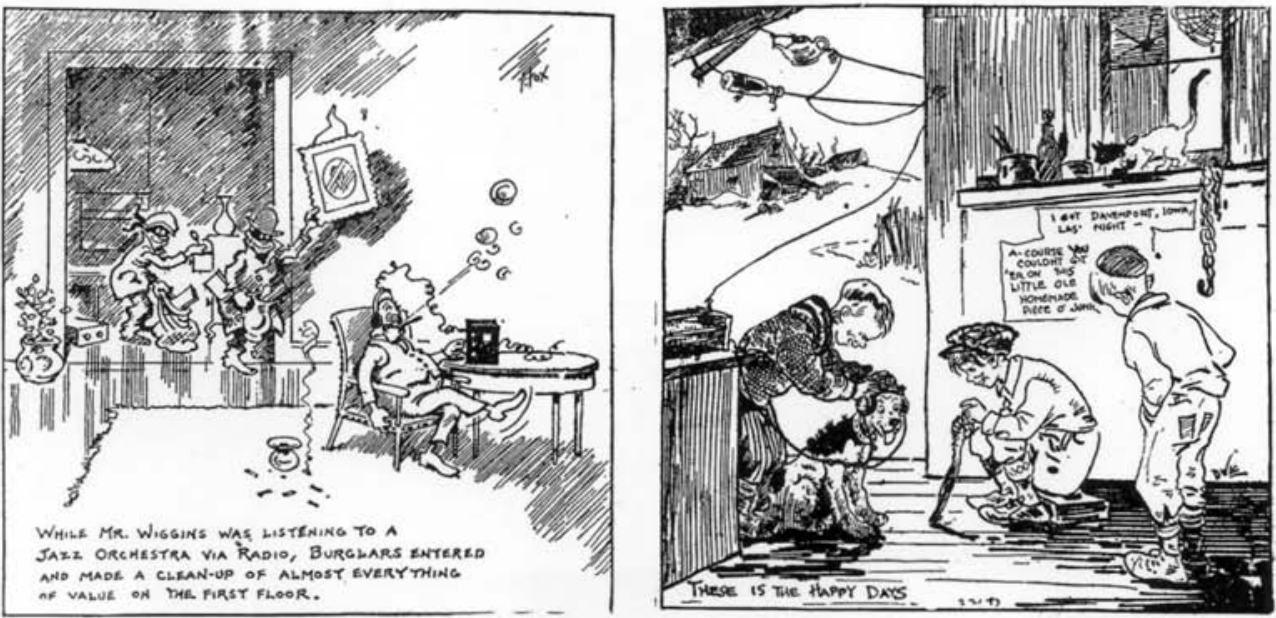

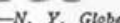

-Philadelphia Public Ledger NOTHING IS IMPORTANT ENOUGH TO TEAR A MAN AWAY FROM HIS RADIO

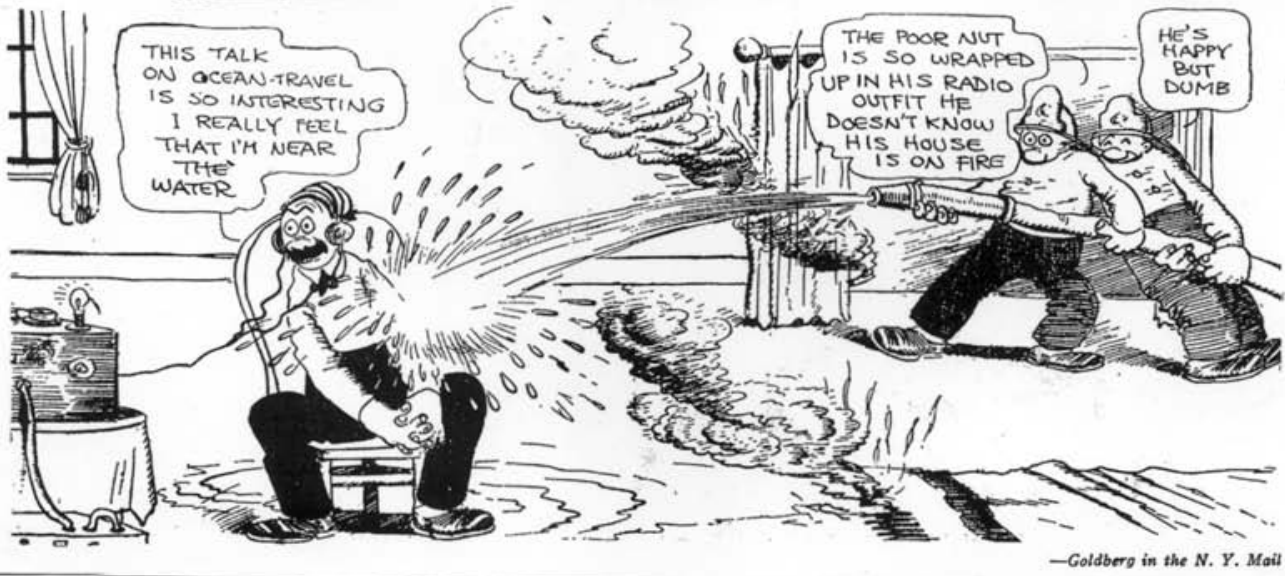

Fig. 10 Cartoons from the April 1923 Wireless Age. Source: National Museum of American History, Washington D.C., USA 
mon motif in the 'radio boom' of the early ig2os. Beginning at the margins of middle-class culture, audile technique first came to be a distinguishing feature of medicine and telegraphy. Rather than 'revolutionizing' hearing, soundreproduction technologies would expand on and further disseminate constructs of listening based on audile technique. Audile technique moved from works on the stethoscope to advertisements for telephony, sound recording, and radio. What took hundreds of pages to explain in the I820s could by the I920s be accomplished within the space of a single page or even the single frame of a comic strip.

Claude Fischer, Susan Douglas, and William Kenney have all persuasively argued that technologies of sound reproduction embodied a diverse range of practices and engendered a diverse range of responses. As Kenney writes, accounts of the diversity of public attitudes toward and responses to a technology represent 'an important corrective to overly simplified, unitary interpretations of "the" influence' of a technology. ${ }^{27}$ It would be too much to claim that audile technique was the single modality through which sound-reproduction technologies were interpreted or used. At the same time, the history of audile technique connects sound-reproduction technologies with the longer history of listening in modernity. The salient features of audile technique considered here - the connection of listening and rationality; the separation of the senses; the segmentation of acoustic space; the construction of sound as a carrier of meaning in itself; and the emphasis on physical, social, and epistemological mediation - are all fundamental to the ways in which people listened to and with sound-reproduction technologies, and all these practices of listening have a long history over the course of the nineteenth century.

For all this, techniques of listening do not simply turn sound technologies into sound media. As Kenney points out, it takes both a shared cultural sensibility and a standardized, industrialized record business to get the same recording to the different people in different places so that they could listen alone together. As the Ayer Agency pointed out on AT\&T's behalf, telephony derived its power and significance from its status as an industrial and technical network, linking together distant people and places so that they could listen alone together. For sound technologies to become sound media, they would have to be articulated together in networks through the organization of new media industries and new middle-class practices.

\section{Notes}

I. This essay is excerpted and edited from Chapters 2 and 3 of The Audible Past: Cultural Origins of Sound Reproduction, Duke University Press, Durham 2003.

2. Nor is it a definitive history of acoustic technique. E. Thompson's Soundscape of Modernity, Cambridge 2002, offers a history of architectural acoustics in America that also deals extensively with questions of sound and technique. 
3. M. Foucault, 'Questions of Method,' in: The Foucault Effect: Studies in Governmentality, eds. G. Burchell, C. Gordon, and P. Miller, Chicago I99I, p. 75, 8I.

4. M. Mauss, 'Body Techniques,' in: Sociology and Psychology: Essays, transl. B. Brewster, Boston I979, p. I04-5.

5. Ibid., p. II2-I9.

6. Ibid., p. Io8.

7. Aristotle, Nicomachean Ethics, transl. M. Ostwald, New York I962, p. I5I-52; M. Heidegger, The Question concerning Technology and Other Essays, transl. W. Lovitt, New York 1977, p. I2; J. Ellul, The Technological Society, New York I964, p. 4, 79-133.

8. P. Bourdieu, The Logic of Practice, transl. R. Nice, Stanford Calif. I990, p. 52-65; P. Bourdieu and L.J.D. Wacquant, An Invitation to Reflexive Sociology, Chicago I992, p. I3-I4, I20-40.

9. Laennec's failed attempt to develop an acoustic lexicon for the stethoscope is discussed in chapter 2 of The Audible Past.

I0. A whole range of writers have contested the notion that hearing is necessarily an imprecise sense. See, e.g., B. Truax, Acoustic Communication, Norwood NJ I984, p.I5-24; and D. Idhe, Listening and Voice: A Phenomenology of Sound, Athens I974, p. 6-8, 58.

II. R. Arnheim, Radio, transl. M. Ludwig and H. Read, London I936; H. Cantril and G. Allport, The Psychology of Radio, New York I935. See also H. Eisler and Th. Adorno, Composing for the Films, New York I947.

I2. Oxford English Dictionary, s.v. 'audile.' Aesthetic preference and convenience also motivate my choice of audile as my adverb and adjective: aural is too easily confused with oral when the word is spoken, and auscultatory seems a bit baroque and is too closely associated with the specific case of medical listening.

I3. For a full discussion, see The Audible Past: Cultural Origins of Sound Reproduction, p. 87-I53.

I4. American Telephone Booth Co., 'Booths of Special Design Made to Match Office Furniture' (I893), NWA, telephone box I, folder 2.

I5. This sense of the possibility of owning communication space is also a tributary formation in the shape of broadcast licensing. See Th. Streeter, Selling the Air: A Critique of the Policy of Commercial Broadcasting in the United States, Chicago I996, p. 219-55.

I6. R. Leppert, The Sight of Sound: Music, Representation, and the History of the Body, Berkeley/ Los Angeles I993, p. I5-4I, esp. 39-40.

I7. Leppert, ibid., p. 24-25. See also J.H. Johnson, Listening in Paris: A Cultural History, Berkeley/Los Angeles 1995; D. Nasaw, Going Out: The Rise and Fall of Public Amusements, New York I993, p. I9-33, I20-34; L. Cohen, Making a New Deal: Industrial Workers in Chicago, 1919-1939, New York I990, p. 99-158; and M. Hansen, Babel and Babylon: Spectatorship in American Silent Film, Cambridge Mass. I99I.

I8. S.J. Reiser, Medicine and the Reign of Technology, London I98I (I978), p. 43-44.

I9. A.B. Davis, Medicine and Its Technology, London I98I, p. I09.

20. MacDowell Associates, Sound: Can It Be Put to Work? How? By Whom? 2, w BA, acoustics box I, folder 3. For a history of architectural acoustics, see E. Thompson, 'Mysteries of the Acoustic: Architectural Acoustics in America, I800-I932' (Ph.D. diss., University of Pennsylvania, I992).

2I. On the commodification of music, see A. Durant, Conditions of Music, Albany I984; E. Eisenberg, The Recording Angel: The Experience of Music from Aristotle to Zappa, New York 1987 , p. II-34; and M. Chanan, Musica Practica: The Social Practice of Music from Gregorian Chant to Postmodernism, New York 1994, and Repeated Takes: A Short History of Recording and Its Effects on Music, New York 1995.

22. W.H. Kenney, Recorded Music in American Life: The Phonograph and Popular Memory, 18901945, New York I999, p. 4.

23. Ibid. This aspect of recording is a fundamental condition for large-scale musical-cultural phenomena. See, e.g., G. Rodman, Elvis after Elvis: The Posthumous Career of a Living Legend, New York 1996.

24. Johnson, Listening in Paris, p. 284.

25. 'Your Telephone Horizon' (I9I2), NWA, box 2I, folder I. 
26. N. Elias, The Civilizing Process: Sociogenetic and Psychogenetic Investigations, transl. E. Jephcott, ed. E. Dunning, J. Goudsblom, and St. Mennell, rev. ed., Malden 2000, p. II8-I9.

27. Kenney, Recorded Music in American Life, p. 7. See also C.S. Fischer, America Calling: A Social History of the Telephone, Berkeley/Los Angeles I992, p. 5; and S. Douglas, Listening In: Radio and the American Imagination from Amos ' $n$ Andy and Edward R. Murrow to Wolfman Jack and Howard Stern, New York I999, p. 7-8, 2I. 